\title{
DERMATOMYOSITIS IN CHILDHOOD A REPORT OF FOUR CASES
}

\author{
BY \\ NORMAN S. CLARK, B.Sc., M.B., Ch.B., M.R.C.P., D.C.H. \\ Medical Registrar, Royal Aberdeen Hospital for Sick Children
}

The purpose of this paper is to describe four cases of dermatomyositis in children, which were seen in the Royal Aberdeen Hospital for Sick Children in the past five years. Though dermatomyositis is probably not an extremely rare disease, the number of cases previously reported, particularly in childhood, is not high, and the etiology and essential pathology are still obscure. Dermatomyositis may be defined as a disease process running, as a rule, a sub-acute or chronic course over a period of months or sometimes years, and characterized in childhood by pyrexia in the early stages, by skin rashes-frequently intermittent, commonly erythematous in type, and, in some cases, progressing to generalized scleroderma; by a firm oedema of the skin and subcutaneous tissues, especially of the malar regions and the extremities, and by pain, weakness, atrophy, and sometimes sclerosis of the limb muscles. From this picture, however, individual cases may show wide variations, particularly in the skin lesions, which may be urticarial, telangiectatic, erysipeloid, or purpuric in nature, and in the extent to which the brunt of the disease falls on the skin, the muscles, and the connective tissues. A number of cases have also been reported in which the mucous membranes have been involved.

Most authors appear to agree with Langmead's view (1923) that dermatomyositis does not, by itself, constitute a disease entity, but falls into a group of conditions which includes also diffuse scleroderma, sclerodactyly, myositis fibrosa, and calcinosis universalis. Cases intermediate in symptomatology between the typical syndromes commonly described by these titles have not infrequently been reported. (Trower and Thursfield, 1921 ; Lewis, 1940; Dowling, 1940.) Dowling (1940) and Freudenthal (1940) have shown that the histological picture seen in the muscles in dermatomyositis is not essentially different from that in diffuse scleroderma. Calcinosis universalis may be more in the nature of a sequel to dermatomyositis or scleroderma than a variant of either syndrome, but may also occur independently of these conditions. Infection of unknown type and origin is generally considered to be the essential factor in the etiology of dermatomyositis, but perusal of the literature provides little concrete proof of this. Karelitz and Welt (1932) discuss the various suggested causes, which include septicaemia, tuberculosis, toxaemia from food poisoning, and protozoal infestation: they consider that, in the two cases which they describe, the rise in temperature after massage during the acute stage, and after the removal of muscle for biopsy, supports the theory of infection: 'Unless an infection or toxin was stirred up, we are at a loss to explain this observation.' They also consider the microscopic appearance of the affected tissues suggestive of inflammation. Dowling (1940), on the other hand, thinks that the histological picture of the muscles is that of ' a degenerative myopathy, not a myositis.' Freudenthal (1940) states that most authors are disinclined to regard the lymphorrhages, which are constantly found in the affected tissues, as an inflammatory reaction; he draws attention to their resemblance to those found in the muscles in hyperthyroidism and myasthenia gravis. Griffiths (1940) also points out the resemblance between certain metabolic disturbances found in dermatomyositis (creatinuria and peripheral insulin resistance) and those seen in certain endocrine diseases, e.g. goitre, acromegaly, and pituitary basophilism.

The prognosis in dermatomyositis is usually serious. Karelitz and Welt (1932), reviewing the literature, were able to collect eighteen cases of dermatomyositis in childhood, and they themselves added two more: of the twenty patients, eight died. Hecht (1940) described five cases, with two deaths. In the majority of fatal cases death is due to intercurrent pneumonia or sepsis. Of the victims who survive, the majority have a prolonged period of invalidism, varying from three months to several years, and a number are left with muscular atrophy and contractures. Treatment has been entirely symptomatic or empirical, and has generally appeared to have little influence on the course of the disease.

\section{Report of Cases}

All temperatures quoted are rectal. Haemoglobin estimations are by the Haldane method. The Westergren technique, with one-hour readings, is used for the erythrocyte sedimentation rate.

Case 1. A girl, aged ten years, was admitted on December 8, 1940, with the history that eleven weeks previously she had had a sore throat and scarlatiniform rash, but no obvious pyrexia or malaise. Symptoms had cleared up spontaneously after twenty-four hours. She remained well for 
four weeks, then developed red blotches and hard lumps on her arms and legs. Two weeks later the muscles of the arms began to feel hard, and the red blotches increased in number, especially when she was hot. Some hardness of the face was then noted, and her arms and legs gradually became stiff and weak. There was nothing significant in her previous history or family history; she was an only child and, although always thin and pale, had been very active.

EXamination on aDmission. She was a pale, toxic-looking, slightly jaundiced child. The temperature was $98 \cdot 8^{\circ} \mathrm{F}$., the pulse 104 , and the respiration 22. Tonsils were large and infected, but the mouth and throat were otherwise healthy. Heart, lungs, and central nervous system were normal. The liver was 2 inches below the costal margin; the spleen was just palpable. The skin and subcutaneous tissues of the face were hard, especially over the masseters and forehead; the face was very pale and rather expressionless, with movements limited - the 'alabaster facies.' The skin over the trunk showed an urticarial rash but no areas of induration. On the arms and legs the skin, subcutaneous tissues, and muscles were generally indurated and oedematous, and the skin was rough, especially in the flexures. On the legs there was a scattered reddish urticarial rash.

LABORATORY FINDINGS. The erythrocyte sedimentation rate was $20 \mathrm{~mm}$.; the red cell count $3,970,000$ per c.mm. of blood; haemoglobin 62 per cent.; white cell count 3,400 per c.mm. of blood (polymorphs 51 per cent., lymphocytes 39 per cent., monocytes 6 per cent., eosinophils 3 per cent., basophils 1 per cent.). Bile pigment and a trace of albumin were present in the urine. The icteric index was 15 . The van den Bergh reaction was positive, indirect; the Wassermann was negative. Serum calcium was $7.8 \mathrm{mg}$. per $100 \mathrm{c.cm}$. of blood, serum phosphate was $3.6 \mathrm{mg}$., and serum cholesterol, $120 \mathrm{mg}$.

Progress. For the next two weeks there was little change in her general condition; she remained afebrile, and her jaundice at first became slightly deeper, then slowly faded and disappeared. An irregular, slightly raised, ' map-like' erythematous rash came and went on the trunk and lower extremities, in places leaving behind some brownish staining. An erysipeloid rash appeared for a few days under the chin. The induration showed no change. Estimation of total urinary creatinine and calcium output over twenty-four-hour periods gave the following results:

December 18. Creatinine $320 \mathrm{mg}$. Calcium $125 \mathrm{mg}$. $\begin{array}{ll}, & 19 . \\ , & 21 .\end{array}$

$\begin{array}{ll}, & 365 \\ , & 388,\end{array}$

", $122, "$

The average creatinine excretion was normal; no creatinine was present, which is unusual; calcium excretion was probably above normal for a child of this age.

December 30.- Some softening of the tissues of the face was noted, but otherwise there was no change: the irregular erythematous rash was still coming and going on the trunk and lower limbs.

On January 22, 1941, the white blood count was 14,400 per c.mm. of blood, polymorphs were 54 per cent., lymphocytes 38.5 per cent., monocytes 3.5 per cent. and eosinophils 4 per cent.
January 31.-The rash had now appeared on the left forearm and had broken down in one or two places, leaving small raw areas which healed slowly during the next three weeks.

February 18.- An annular rash, suggesting urticaria circinata, appeared on the abdomen.

March 4.-The right ankle became swollen and painful, and she developed an irregular pyrexia, which on one occasion reached $103^{\circ}$ F., and which settled after a week. During this week the swelling and pain in the ankle subsided, and the left wrist became swollen and painful for a few days. Thereafter her condition steadily improved, the rash faded, and the induration and oedema of skin and subcutaneous tissues slowly disappeared. She was discharged on April 15 after skiagrams of the soft tissues had shown no evidence of calcinosis.

She was seen again in the out-patient department on June 11 and on September 24, 1941, when she was reported to be having occasional urticarial rashes and, at times, slight clonic movements of the left arm and leg. Examination of the central nervous system showed nothing abnormal, and there was no wasting, and no induration or oedema.

Case 2. A girl, aged eight years, was admitted on March 20,1942, with the history that three months ago she began to stand and walk with her knees slightly bent. A few weeks later her feet began to swell, the swelling being more marked after walking for some time. The calves of the legs gradually became swollen and stiff, and about a week later the arms and hands became similarly affected. She had never complained of pain. There was nothing significant in her personal or family history. She was the fourth child in a family of six, and had always been healthy.

EXAMINATION ON ADMISSION. The general condition was good; the temperature was $99 \cdot 8^{\circ} \mathrm{F}$., the pulse 112, and respiration 26. The mouth, throat, heart, lungs, abdomen, and central nervous system were normal. There was some generalized loss of elasticity of the skin, but no rash: the muscles were indurated in the arms and legs and, to a less extent, in the abdominal wall and left pectoral region. The joints moved freely. The urine was normal. Skiagrams of the limbs showed some generalized rarefaction of bone, but no evidence of calcinosis.

PROGRess. For the next two weeks the child ran a low, irregular pyrexia, never exceeding $100 \cdot 6^{\circ} \mathrm{F}$., and thereafter remained afebrile. During the first week an irregular blotchy erythematous rash appeared intermittently on the back and extensor surface of the arms: muscular stiffness varied from day to day.

March 28.- Three irregular areas of pale, glazed, abnormally hard and transparent skin had appeared on the lumbar region. On the flexor aspect of the arms the skin was firmer than normal, and tended to become fixed to the underlying tissues. A differential count at this time showed an eosinophilia of 13 per cent., but a total white blood count was not taken.

During the next month the sclerodermatous areas on the back showed no change, but there was a very slow improvement in the consistency of the limb muscles, the peripheral ones remaining harder than the proximal.

May 18.-The patches of scleroderma on the 
back had decreased slightly in size, but another patch had appeared on the dorsum of the right hand. There had been a further slight improvement in the muscles, but movements of the fingers and elbows were still extremely stiff.

June 30.- She was able to walk a little with support, but improvement was very slow and there was still marked weakness of all limb muscles and stiffness of the forearm muscles. A few small patches of scleroderma had appeared on the adjacent surfaces of the fingers.

July 29.-No further improvement was noted. She was discharged to lie at home, continue exercises, and wear night splints to prevent contractures.

September 23.-She was seen in the out-patient department. There had been some improvement in the muscular condition, but some new areas of scleroderma had appeared on the back.

March 24, 1943.- She was again seen in the outpatient department. There had been a marked deterioration in her condition. Wasting and induration of all limb muscles had increased considerably, and there was marked limitation of movement in the elbows, wrists, and fingers. The skin of the legs was hard and shiny, and the sclerodermatous areas on the back were whiter.

April 12.- The child was re-admitted to hospital. Her condition was as above. Skiagrams of whole body showed no evidence of calcinosis. She remained in hospital till August 6, and during this period there was a very slow improvement in all the muscles. This improvement was interrupted by a mild attack of Sonne dysentery, during which there was a marked increase of muscular stiffness and weakness. She was afebrile during the whole of this period, and treatment consisted only of massage and exercises.

May 10.- She was seen in the out-patient department. She was much improved. She was now able to cycle two miles to school daily, but the muscles of the arms and forearms were still hard, and movements of the wrists and elbows still limited. There were several patches of scleroderma on the chest in addition to those previously noted.

When seen again on November 25,1944 , and on April 4, 1945, she had a contracture of the flexor muscles of the right forearm, but all other movements were full. The muscles of legs and thighs were still wasted and rather hard. The scleroderma was unchanged.

February 14, 1946.- The flexion deformity of the right wrist was still present, though less marked. The forearm muscles were still rather hard, and the leg muscles weak. The sclerodermatous patches had disappeared, except in the lumbar and lower dorsal regions, where there were well-defined areas of pale, atrophic skin, which were of almost normal elasticity.

Case 3. A girl, aged six years, was admitted on December 8, 1942, with the history that she had developed a sore throat five weeks previously, after which some swelling of the face, neck, and arms appeared, and the arms had become rather stiff: movement of the elbows was painful. The legs were unaffected. She was the only child of healthy parents and there was nothing significant in her personal history.

EXAMINATION ON ADMISSION. The general condition was good; the temperature was $100^{\circ} \mathrm{F}$., the pulse 110 , and the respiration 20 . The tonsils were slightly enlarged. The heart, lungs, abdomen and central nervous system were normal. The skin was red, fissured, and rough at the flexures of the elbows and wrists. There was widespread induration of the skin and subcutaneous tissues, this being most marked on the face. The brow was firm and pale, 'like alabaster.' The arms were slightly swollen, the muscles hard and wasted, but with movements almost full. The trunk and legs were less involved, but the skin was slightly firmer than normal and the calf muscles hard. Skiagrams of the arms showed no evidence of calcinosis. A differential leucocyte count showed no eosinophilia.

Progress. A course of sulphanilamide, $0.5 \mathrm{~g}$. four-hourly, was started on admission and continued till December 12, 1942 (total $12 \mathrm{~g}$.). The temperature fell to normal at once and remained so till December 13, when she began to run a low irregular pyrexia (never exceeding $100 \cdot 2^{\circ} \mathrm{F}$.). Sulphathiazole, $0.5 \mathrm{~g}$. four-hourly, was given from December 15 to 21 (total $18 \mathrm{~g}$.). But the pyrexia did not subside completely. During this period there had been no change in the condition of the skin or muscles, but on December 24 the induration of the skin, especially in the neck, seemed slightly less marked.

January 2, 1943.-An acute pharyngitis developed (temperature $103^{\circ} \mathrm{F}$.), and another course of sulphanilamide, $0.5 \mathrm{~g}$. four-hourly, was begun, and continued till January 6 (total $10.5 \mathrm{~g}$.), by which date the pharyngitis had cleared, though the temperature still rose to $100^{\circ} \mathrm{F}$. on most evenings. Improvement of the induration of skin and muscles continued, and on January 20 she was discharged to rest at home.

April 14.- She was seen as an out-patient. There was marked general improvement, though the forearm muscles were still hard.

October 27.- She again reported as an outpatient. The condition had cleared up completely, leaving no disability.

Case 4. A girl, aged four years, was admitted on October 8, 1945, with the history that one week previously, after a blow with a stone, her right ankle became swollen and painful. Her hands then began to swell and became discoloured, and she complained of pain in all her limbs and was very resentful of any movement. She had been feverish all the week. She was the sixth child in a family of eight, and there was nothing significant in the family history. One year previously she had been ill for about a month-with pain and swelling of all her limbs-and had been treated at home as a case of 'acute rheumatism.' The previous history was not otherwise significant.

EXAMINATION ON ADMISSION. She was a rather ill-looking and extremely miserable child, who appeared terrified of any attempt to move her limbs. Her temperature was $103^{\circ} \mathrm{F}$., the pulse 136 , and the respiration 30 . The tonsils and related lymph nodes were enlarged. The heart, lungs, abdomen, and central nervous system were normal. On the cheeks and on the dorsum of the hands there was irregular purple mottling which in places was slightly hard to the touch. There was slight subcutaneous oedema of both hands and feet. No induration was palpable in the limb muscles, which 
were generally acutely tender. Any movement of the limbs appeared to cause severe muscular pain. Urine was normal, and blood culture sterile.

Progress. On the day following admission some diffuse swelling appeared over both malar regions. One week after admission her temperature had been normal for three days, but her pulse was still rapid, and a systolic murmur had appeared at the mitral area. Pain was less, but she still resented any movement of the limbs. The swelling and irregular purplish erythema persisted. The erythrocyte sedimentation rate was $65 \mathrm{~mm}$.

October 23.- She again began to run an irregular pyrexia, and on October 29 limb pains were aggravated. The oedema of the left foot had spread as far as the knee. The purplish mottling noted on admission had spread to the forearms, thighs, and buttocks, some of the affected patches being indurated and giving the impression of subcutaneous nodules. The axillary and inguinal lymph nodes were somewhat enlarged and tender. Urine was normal. Skiagrams of the chest and all limbs showed no abnormalities.

November 15.-Pyrexia persisted, but pain was slightly less and the lymph nodes were no longer enlarged. The mitral systolic murmur was still present. A blood culture was sterile.

November 25.-The red cell count was 3,330,000 per c.mm. of blood. Haemoglobin was 52 per cent., the white cell count 34,700 per c.mm. of blood, polymorphs 76 per cent., lymphocytes 17 per cent., monocytes 5 per cent., eosinophils 1 per cent. and basophils 1 per cent. As there had been no further improvement it was decided to try the effect of a course of penicillin-100,000 units per day by intramuscular drip. This was continued till November 29 (total 500,000 units). Although the pyrexia had not settled completely, her general condition greatly improved during this period, and she moved her limbs much more freely and with little pain. Muscle power was fair, but there was considerable wasting of all limb muscles. Agglutinations to brucella abortus were negative.

During the next month her pyrexia never settled completely, but the general improvement was maintained and she was at times completely free from pain. The purplish mottling on the skin tended to disappear in some areas, leaving behind a faint brownish staining; but it reappeared in other areas and showed no real improvement. The subcutaneous nodules became more easily palpable on the thighs and buttocks.

December 30.-Her temperature was tending to rise, and she was again very miserable and complained of severe pain in the arms and legs. There was now much wasting and weakness of all limb muscles. Penicillin, 100,000 units daily, divided into four-hourly doses, intra-muscular, was restarted. Administration of penicillin was continued from December 30, 1945, to January 9, 1946 (total 950,000 units). Her temperature was then normal, and it did not rise again. There had been considerable improvement in her general condition during this course, and she was now free from pain. The subcutaneous nodules were now less obvious, though the purplish mottling of the skin was still present. There was still some tachycardia, but the mitral systolic murmur was less obvious.

January 31.-Her condition had shown steady improvement in spite of an attack of pharyngitis with a sharp rise of temperature for a few days. No subcutaneous nodules were palpable, her muscles were neither painful nor tender, and wasting had begun to disappear. The purplish mottling was still present on the skin of the face, forearms, thighs, and buttocks, but this tended to come and go and was much less widespread. Some of the previously affected areas still showed faint brown pigmentation.

February 16.- The patient was discharged; she was still weak but was rapidly regaining her muscular power. The mottling was now very faint, and was present only on the skin of the thighs. The tachycardia had settled, and the systolic murmur had disappeared. Skiagrams of soft tissues showed no evidence of calcinosis.

April 3.- She reported as an out-patient. She was very well and the muscular wasting was much lessened. There were still a few pigmented areas on the thighs, but no other skin changes.

\section{Discussion}

Etiology. Although the etiology of the above four cases was not established, there seems to be some circumstantial evidence in favour of the infective hypothesis. Without postulating the presence of infection it is very difficult to explain the excellent response of case 4 to penicillin. Even after the first course of 500,000 units there was a very decided improvement in the patient's general condition, although her temperature failed to settle completely. It was, perhaps, fortunate from the scientific point of view that the total dosage of the first course was apparently inadequate to eradicate the infection, because it might well have been coincidence that the administration of penicillin was followed by clinical improvement: spontaneous resolution or remission may occur at any stage of the disease. The fact that, after the patient had relapsed, a second course of penicillin was again immediately followed by great improvementwhich proceeded to complete resolution of the disease - considerably increases the probability that penicillin was, in fact, responsible for the improvement. The history of antecedent sore throat in cases 1 and 3 , and evidence of previous tonsillar infertion in case 4, also tend to support the infective theory and to suggest a possible portal of entry for the infecting organism.

Sex incidence. The fact that all four cases described were females appears to be fortuitous. Of the twenty cases collected by Karelitz and Welt (1932), eleven were male and nine female.

Symptomatology. The four cases above described conform in general to the accepted clinical picture of dermatomyositis and illustrate well the considerable diversity which may occur in this picture. A!! four cases showed evidence of involvement of both skin and muscle, but in case 1 the main brunt of the disease appeared to fall on the skin, in cases 2 and 3 on the muscles. In case 4 skin and muscles appeared to be equally involved. Case 1 shows how varied the skin manifestations in this disease can be, the rash at different times being erythematous, 
urticarial, and erysipeloid in character. The erythematous rash in case 4 was of a peculiar purplish hue, a point noted also by Stuckey (1935) and Sheldon and Evans (1936). Only case 2 showed any tendency to sclerodermatous change; this was widespread on the trunk at one stage, but most of the patches resolved completely. A peculiar firm oedema of the skin, which did not show pitting on pressure, was present in three out of the four cases. In the face, where this symptom seems to appear most frequently, it produces a typical mask-like ' alabaster facies' which is practically pathognomonic of dermatomyositis.

In all cases except case 1 , the muscles showed marked wasting; and, in all cases except case 4, they felt abnormally hard. An undue firmness of the muscles is described by Karelitz and Welt (1932) as frequently being present, but this is not an essential feature of the disease. In the five cases described by Hecht (1940) the muscles were said to show gross wasting, but there was no mention of firmness. It seems reasonable to suppose that the consistency of the muscles in the earlier stages of the disease, before fibrosis or contractures have occurred, may depend on the presence or absence of oedema; and the oedema may doubtless vary in the muscles as it does in the skin and subcutaneous tissues. Freudenthal (1940) states that there may be oedema both of the muscle fibres and in the perimysium. Only in case 4 was muscular pain a prominent feature-from which it may be concluded that, whatever the mechanism of its production, pain is not due to tension, for this case showed no induration or swelling of the muscles at any time. The muscles of deglutition and respiration, which are said to be sometimes involved, escaped in all four cases here reported; and only in case 4 , in which there was persistent tachycardia and a mitral systolic murmur, was there any evidence of myocardial involvement.

The jaundice noted in the early stages of the disease in case 1 was probably incidental, for its course appeared to be independent of the course of the dermatomyositis. Cases of infective hepatitis were known to have occurred about the same time in the district from which the patient came.

Pathology. It is regretted that, owing to war-time shortage of staff, these cases were not investigated more fully, and in particular that no biopsies of skin and muscle were done.

It is remarkable that no creatinuria was discovered in case 1-the only case which was investigated from this point of view-for Griffiths (1940) states that a very considerable creatinuria was present in all the cases of dermatomyositis which he had investigated. Moreover, small amounts of creatine are normally present in the urine in childhood. It may be significant that, in case 1 , muscular involvement was minimal; creatinuria is probably an indication of disordered muscle metabolism.

Prognosis. The final results in these four cases were much better than might have been expected, judging from previous reports of dermatomyositis in childhood. It appears to be unusual to see four cases who all recover and who have, except for the contracture of one group of muscles in one case, no terminal disability.

In no case was there any evidence of calcinosis, which appears to be a not uncommon sequel to dermatomyositis. Four out of five cases described by Hecht (1940) developed the condition, but this is probably an unduly high incidence. It is interesting to speculate whether the administration of disodium hydrogen phosphate (which was given over prolonged periods, in dosage of 60 gr. t.d.s. to cases 1,2 , and 3 ) had any influence in preventing the development of calcinosis in these cases. Craig and Lyall (1931) reported a case of calcinosis universalis in which administration of this drug had a remarkable effect in reducing the calcium deposits.

Treatment. The difficulty of escaping the conclusion that penicillin was responsible for the arrest of the disease in case 4 has already been mentioned. Obviously no final conclusions can be drawn from a single case, but it would certainly appear worth while to investigate further the effect of penicillin in this disease: if the effect here described can be confirmed, a very real advance will have been made, for hitherto no treatment has appeared to have any effect. The response of case 3 to sulphonamides was too indefinite for any conclusions to be drawn from it, but it did seem that the sulphonamides were of some benefit and might have been responsible for the comparatively mild course of this case. There appears to be no previous reference in the literature to the treatment of dermatomyositis with either sulphonamide or penicillin.

\section{Summary}

Four cases of dermatomyositis in childhood are described.

Some circumstantial evidence is given in favour of the theory that this disease is due to infection.

The diversity of the clinical picture is discussed, and is compared with that in previously described cases.

The favourable effect of penicillin in one case is described, and it is suggested that this drug is worthy of further trial.

My thanks are due to Dr. John Craig for advice and encouragement in the preparation of this paper, and for permission to report cases treated in his ward.

\section{REFERENCES}

Craig, J., and Lyall, A. (1931). Brit. J. Child. Dis., 28, 29. Dowling, G. B. (1940). Brit. J. Derm. Syph., 52, 242. Freudenthal, W. (1940). Ibid., 52, 289.

Griffiths, W. J. (1940). Ibid., 52, 295.

Hecht, M. S. (1940). J. Pediat., 17, 791.

Karelitz, S., and Welt, S. K.'(1932). Amer. J. Dis. Child., 43, 1134.

Langmead, F. S. (1923). Arch. Pediat., 40, 112.

Lewis, T. (1940). Brit. J. Derm. Syph., 52, 233.

Sheldon, W., and Evans, P. R. (1936). Proc. roy. Soc. Med., 30, 109.

Stuckey, E. S. (1935). Brit. J. Derm. Syph., 47, 85.

Trower, G. S., and Thursfield, H. (1921). Proc. roy. Soc. Med.'(Sec. Dis. Child.), 14, 90. 